\title{
Effective removal of heavy metal by biochar colloids under
} different pyrolysis temperatures

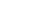

Linbo Qian, Wenying Zhang, Jingchun Yan, Lu Han, Weiguo Gao, Rongqin Liu and Mengfang Chen ${ }^{*}$

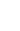

Key Laboratory of Soil Environment and Pollution Remediation, Institute of Soil

Science, Chinese Academy of Sciences, Nanjing 210008, Jiangsu Province, China.

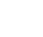

10

1

* Corresponding Author E-mail: mfchen@issas.ac.cn

Phone: $+86-25-86881847$

Fax: $+86-25-86881126$

\section{5}

(6)

(7)

* Corresponding Author Telephone: +86-25-8688-1847, Fax: +86-25-8688-1126

E-mail: mfchen@issas.ac.cn 


\section{Abstract}

22 Biochar colloids' association with heavy metal needs be studied to precisely evaluate 23 the effectiveness of biochar as sorbents. The structure of biochar colloids and their roles 24 in heavy metal removal were investigated by Fourier-Transform Infrared Spectroscopy, 25 X-Ray Diffraction and batch adsorption experiments, respectively. Due to the numerous oxygen function groups and mineral matters contained in biochar colloids, the removal capacity of chromium $(\mathrm{Cr})$ and cadmium $(\mathrm{Cd})$ to biochar colloids was much greater than that of biochar residues. The highest adsorption capacities of $\mathrm{Cr}(\mathrm{III})$ and $\mathrm{Cd}(\mathrm{II})$ under initial pH 3.5 were obtained by RS400, which were mainly attributed to the presence of oxygen function groups and mineral matters simultaneously. The highest removal capacity of $\mathrm{Cr}(\mathrm{VI})$ was observed by RS300 due to the additional reduction by phenolic functional groups of RS300C. Therefore, the functions of biochar colloids for heavy metal removal should be considered.

Keywords: Biochar colloids; Cadmium; Chromium; Adsorption; Reduction. 
Biochar is often charred from biomass, and it is considered a novel and practical approach in the biowaste treatment and pollution remediation (Chen et al., 2012; Chen et al., 2008; Fang et al., 2015; Qian et al., 2013; Uchimiya et al., 2011; Yan et al., 2015). An increasing number of studies have shown that the organic components and inorganic ions of biochar played dominant roles in the immobilization of heavy metals (Cao \& Harris, 2010; Qian \& Chen, 2013; Qian \& Chen, 2014; Qian et al., 2015; Uchimiya et al., 2011). Generally, the heavy metal immobilization by these constituents of biochar not only happens to biochar surfaces, but also reacts with the dissolved matters (Chen et al., 2015; Dong et al., 2014; Hsu et al., 2009). The oxygen-containing functional groups of the dissolved matter of biochar could lead to hexavalent chrome reduction and the dissolved phosphorus could co-precipitate with heavy metals (Shen et al., 2012; Zhang et al., 2013; Zheng et al., 2012). Typically, the most of these active components organic molecules etc., making the association of heavy metals with colloids more complex (Gao et al., 2011; Sen \& Khilar, 2006). Due to the heterogeneous nature, biochar exhibits mutable properties, which depend on the biomass and pyrolysis 
temperatures (Cantrell et al., 2012; Chen et al., 2008). Furthermore, as a series of

65 biochar dissolving and break down would happen after biochar amendment to the

66 environment, it is important to understand the interaction processes of such components

67 with heavy metals. The effects of particles and pyrolysis temperatures on the transport and retention behaviors of biochar colloids were investigated (Wang et al., 2013a; Zhang et al., 2010). However, relatively less attention has been paid to the association of biochar colloids with heavy metals.

The main objective of this study was to evaluate the interaction of biochar colloids and heavy metals (trivalent chromium $(\mathrm{Cr}(\mathrm{III}))$, hexavalent chrome $(\mathrm{Cr}(\mathrm{VI}))$ and Cadmium $(\mathrm{Cd}(\mathrm{II})))$. The different biochar colloids were obtained from rice straw pyrolysed at a series of temperatures $\left(100,300,400,500\right.$ and $\left.700^{\circ} \mathrm{C}\right)$. Then the structures of biochar colloids and biochar residues were analyzed by Elemental Analyses, Fourier-Transform Infrared Spectroscopy (FTIR) and X-Ray Diffraction (XRD). The interaction of biochar colloids with heavy metals was observed by batch adsorption experiments with $\mathrm{pH}$ ranging from 1.5 to 4.5 . Finally, the mechanism of biochar colloids for the adsorption of heavy metals was interpreted and implications for risk assessment were discussed.

\section{Materials and Methods}

2.1 Preparation of biochars and biochar colloids

A crop residue (rice straw (RS)) was collected from the Changshu Agroecological 
biochars were prepared by charring rice straw under anaerobic conditions under varying temperatures. The procedure of preparing the biochars is in accordance with a modified method (Qian \& Chen, 2013). Briefly, the rice straw was air-dried for 2 days before being oven-dried overnight at $70-80{ }^{\circ} \mathrm{C}$. Then the biomass sample was grounded and passed through a $0.154 \mathrm{~mm}$ sieve. The powdered biomass was tightly packed into a ceramic pot and covered with a fitted lid before being pyrolyzed for $6 \mathrm{~h}$ at different temperatures $\left(100,300,400,500\right.$ and $\left.700{ }^{\circ} \mathrm{C}\right)$ in a muffle furnace under an oxygen-limited atmosphere. The heating rate was controlled at $5{ }^{\circ} \mathrm{C} / \mathrm{min}$ for slow pyrolysis. Biochars produced at $100,300,400,500$ and $700{ }^{\circ} \mathrm{C}$ are here labeled respectively as RS100, RS300, RS400, RS500 and RS700. The biochars were passed through a $0.154 \mathrm{~mm}$ sieve prior to prepare biochar colloids. The procedure of preparing the biochar colloids was modified from a previous method (Wang et al., 2013a). Briefly, $6.0 \mathrm{~g}$ of biochars was added to $500 \mathrm{~mL}$ of distilled water, gently stirred for $1 \mathrm{~min}$, and then sonicated (100 W, $45 \mathrm{kHz}, \mathrm{KQ}-600 \mathrm{VDB}$ sonicator, Kunshan, China) in a water bath for $30 \mathrm{~min}$ to disperse the suspension. After settling for a fixed time based on Stokes Law, the suspension particle size was less than $2 \mu \mathrm{m}$, and was designated as biochar colloids (Wang et al., 2013a). Then the solid and liquid was separated, the liquid suspension of biochar samples were named biochar colloids, marked as RS100C, RS300C, RS400C, RS500C and RS700C, and the solids of biochar samples were named as biochar residues, marked as RS100R, RS300R, RS400R, RS500R and RS700R. The biochar colloids and residues were dried and passed through a $0.154 \mathrm{~mm}$ sieve before 
use.

2.2 Sample characterization

The samples of biochar colloids and biochar residues were characterized by

Elemental Analyses (Vario Macro CHNS-O-CL, Elementar, Germany) and Fourier-Transform Infrared Spectroscopy (FTIR, Thermo Scientific 7600, USA), X-Ray Diffraction (XRD, RIGAKU D/MAX 2550/PC, Japan). The elemental (Carbon (C), Hydrogen $(\mathrm{H})$, Oxygen $(\mathrm{O})$ and Nitrogen $(\mathrm{N})$ ) analyses of biochar colloids and residues were conducted with the Elemental Analyses. For FTIR analyses, biochar samples were treated by $\mathrm{KBr}$ wafers with a 1/100 mass ratio, grounded and pressed into lamellar forms. The samples were recorded between 4000 and $400 \mathrm{~cm}^{-1}$ by the FTIR (with $0.01 \mathrm{~mol} / \mathrm{L} \mathrm{NaCl}$ as a background electrolyte), and the initial $\mathrm{pH}$ ranged from 1.5 
$\mathrm{NaOH}$. The adsorption experiments including the blank and calibration control were performed in duplicate. The mixture was subsequently agitated on a reciprocating shaker at $150 \mathrm{rpm}$ and $25 \pm 1{ }^{\circ} \mathrm{C}$ for $24 \mathrm{~h}$. Then the solution was filtered through a 0.22 $\mu \mathrm{m}$ millipore filter. The filtrate was acidified immediately with $0.2 \%(\mathrm{v} / \mathrm{v}) \mathrm{HCl}$ for total $\mathrm{Cr}$ and $\mathrm{Cd}$ analysis. The total $\mathrm{Cr}$ and $\mathrm{Cd}$ concentrations in the supernatant fluid were determined by a Varian Spectra AA220 atomic adsorption spectrometer (Varian, USA). The total $\mathrm{Cr}$ and $\mathrm{Cd}$ were determined at wavelength of $357.9 \mathrm{~nm}$ and $228.8 \mathrm{~nm}$, respectively, the $\mathrm{Cr}(\mathrm{III})$ was taken as the difference between total $\mathrm{Cr}$ and $\mathrm{Cr}(\mathrm{VI})$ values. The $\mathrm{Cr}(\mathrm{VI})$ concentration was determinated by an UV-vis Spectrophotometer (Shanghai Puyuan Alpha-1506 ) with diphenyl-carbazide at $540 \mathrm{~nm}$.

\section{Results and discussion}

3.1 Structural characterization of biochar colloids and biochar residues

As illustrated in Table 1, the element contents of biochar colloids and biochar residues were different as the pyrolysis temperature is increased. When the pyrolysis temperature was at $100{ }^{\circ} \mathrm{C}$, Carbon $(\mathrm{C})$, Hydrogen $(\mathrm{H})$, Oxygen $(\mathrm{O})$ contents were relatively similar between biochar colloids and biochar residues, indicating the organic matters were easily dissolved at $100{ }^{\circ} \mathrm{C}$. The Nitrogen $(\mathrm{N})$ content in the biochar colloids was significantly higher than that in the biochar residues, which illustrated that $\mathrm{N}$ was easily dissolved from biochar at $100{ }^{\circ} \mathrm{C}$. As the charring temperature was increased to $700^{\circ} \mathrm{C}$, the $\mathrm{C}, \mathrm{H}, \mathrm{O}, \mathrm{N}$ contents of biochar colloids were decreased from 
$34.48 \%$ to $24.65 \%, 5.38 \%$ to $1.15 \%, 45.39 \%$ to 27.04 and $1.10 \%$ to 0.01 , respectively. Therefore, the dissolved organic constituents were reduced as the charring temperature was increased, indicating that the biomass pyrolysis to biochar could promote the carbon and nitrogen fixation. The phenomenon was affirmed by the $\mathrm{C}$ and $\mathrm{N}$ contents increased with pyrolysis temperature increasing in biochar residue. Furthermore, the $\mathrm{H} / \mathrm{C}$ ratio of biochar colloids and residues were decreased with the increase of pyrolysis temperature. As the $\mathrm{H} / \mathrm{C}$ ratio is the molar ratio, it is the representative of the degree of carbonization, indicated the thermal alteration of lignocellulose to more condensed aromatic structures (Chen et al., 2008).

The evolution of FTIR spectra of biochar colloids and residues with the increasing pyrolysis temperatures are illustrated in Fig. S1 (Supplementary data). For biochar residues, RS100R was rich in organic and inorganic functional groups, as occurred at $3405 \mathrm{~cm}^{-1}(-\mathrm{OH}), 1732 \mathrm{~cm}^{-1}$ and $1162 \mathrm{~cm}^{-1}$ (ester $\left.\mathrm{C}=\mathrm{O}\right), 1651 \mathrm{~cm}^{-1}$ (aromatic $\mathrm{C}=\mathrm{C}$ ) and between 1200 and $1060 \mathrm{~cm}^{-1}$ (C-O), $1100-1000 \mathrm{~cm}^{-1}, 880-780 \mathrm{~cm}^{-1}$ and $470 \mathrm{~cm}^{-1}$ (Si-O-Si). When the pyrolytic temperature of the biochar was increased further, the functional group were decreased or eliminated. A previous study compared the FTIR spectra of original biochar with washed biochars confirmed that the matters released from biochar could not change its functional group (Xiao et al., 2014). However, the FTIR spectra performance of biochar colloids showed different variation from that of biochar residues. For RS100C, the bands at $3400-3420 \mathrm{~cm}^{-1}, 3000-2800 \mathrm{~cm}^{-1}$ represent the stretching of - $\mathrm{OH},-\mathrm{CH}_{3}$ and $-\mathrm{CH}_{2}$, respectively, which indicated that fatty alcohol 
compounds existed in the biochar colloids. The RS100C exhibits stronger peak intensity at $1384 \mathrm{~cm}^{-1}, 1632 \mathrm{~cm}^{-1}$ and $3405 \mathrm{~cm}^{-1}$ than that of RS100R, which are attributed to $\mathrm{C}-\mathrm{H}$ deformation of aliphatic groups, aromatic $\mathrm{C}=\mathrm{C}$ stretching vibration and $\mathrm{O}-\mathrm{H}$ stretching from the presence of phenols, respectively (Li et al., 2014). A much higher absorption intensity was occurred at the $1632 \mathrm{~cm}^{-1}, 1113 \mathrm{~cm}^{-1}$ and $619 \mathrm{~cm}^{-1}$ bands indicated the presence of the aromatic and polysaccharide contents in biochar colloids (Zhu et al., 2014). Similar to RS100C, such characteristic bands were also identified by the FTIR spectra of dissolved organic matter of biochars derived from rice straws (Matilainen et al., 2011). As the charred temperature was increased to $300^{\circ} \mathrm{C}$, the stronger peak intensity of $\mathrm{C}-\mathrm{H}$ deformation of aliphatic groups $\left(1378 \mathrm{~cm}^{-1}\right)$, aromatic $\mathrm{C}=\mathrm{C}$ stretching vibration $\left(1620 \mathrm{~cm}^{-1}\right)$ and $\mathrm{O}-\mathrm{H}$ stretching $\left(3428 \mathrm{~cm}^{-1}\right)$ were still observed, indicating that the phenol functional groups were remained on the RS300C. As the charred temperatures were further increased in case of RS400C, RS500C and RS700C, the organic functional groups were also decreased or eliminated, and the band of Si-O-Si occurred in biochar colloid indicated high Si dissolution. Remarkably, new bands were found in RS500C and RS700C, such as $1586 \mathrm{~cm}^{-1}$ for RS500C and $1460 \mathrm{~cm}^{-1}, 1116 \mathrm{~cm}^{-1}, 849 \mathrm{~cm}^{-1}$ for RS700C, indicating the appearance of a $\mathrm{C}=\mathrm{C}$ aromatic stretch (Eusterhues et al., 2011; Oren \& Chefetz, 2012).

The X-ray diffraction spectra of the biochar colloids and residues are shown in Fig. S2. The diffraction peaks $(2 \theta)$ between $2 \theta=15$ and 30 in the RS100R were attributed to amorphous organic components (Cao \& Harris, 2010). These components were 
gradually disappeared as the pyrolysis temperature was increased. No crystalline substances were observed in the XRD spectra of RS100R. Previous studies have confirmed this observation (Qian \& Chen, 2013). Unlike the original biochar where the great amount crystalline substances were appeared with increasing pyrolysis temperatures, the crystalline substances of biochar residues were decreased or eliminated. A few crystalline substances, such as calcium oxalate $\left(\mathrm{CaC}_{2} \mathrm{O}_{4}\right)$, calcite $\left(\mathrm{CaCO}_{3}\right)$, sylvite $(\mathrm{KCl})$, quartz $\left(\mathrm{SiO}_{2}\right)$, were appeared in $\mathrm{RS} 300 \mathrm{R}$, RS400R, RS500R and RS700R, respectively. This phenomenon indicated that many crystalline substances were mainly dissolved into the solution to form biochar colloids. The diffraction spectra confirmed the presence of many crystalline substances in biochar colloids._The calcium oxalate $\left(\mathrm{CaC}_{2} \mathrm{O}_{4}\right)$ and sylvite $(\mathrm{KCl})$ were appeared in $\mathrm{RS} 100 \mathrm{C}$. As the pyrolysis temperature was increased, new diffraction peaks for magnesia calcite $\left(\mathrm{MgCO}_{3}\right)$, calcite $\left(\mathrm{CaCO}_{3}\right)$, dolomite $\left(\mathrm{CaMg}\left(\mathrm{CO}_{3}\right)_{2}\right)$ were appeared in $\mathrm{RS} 500 \mathrm{C}$ and $\mathrm{RS} 700 \mathrm{C}$. The presence of quartz and calcite indicated that the rice straw was rich in silicon and the alkaline elements.

\subsection{The heavy metal removal properties by biochar colloids and residues} The effect of $\mathrm{pH}$ on $\mathrm{Cr}(\mathrm{III})$ adsorption by biochar colloids and residues are given in Fig. 1. The $\mathrm{Cr}(\mathrm{III})$ adsorption by biochar residues was gradually increased when the $\mathrm{pH}$ values were increased from 2.5 to 4.5 . The $\mathrm{Cr}$ (III) adsorption by RS100R was increased from 2.4 to $3.1 \mathrm{mg} / \mathrm{g}$ when initial $\mathrm{pH} 3.0$ was raised to $\mathrm{pH} 4.5$. Similarly, the $\mathrm{Cr}(\mathrm{III})$ adsorption by RS300R, RS400R, RS500R and RS700R were also increased with the 
211 increase of the pyrolysis temperature and reached to the highest amount of 5.2, 6.5, 3.5 212 and $3.5 \mathrm{mg} / \mathrm{g}$ at initial $\mathrm{pH} 4.5, \mathrm{pH} 3.9, \mathrm{pH} 3.3$ and $\mathrm{pH} 3.5$, respectively. It is apparent that 213 the $\operatorname{Cr}(I I)$ adsorption capacity was not efficient. This was mainly attributed to the 214 alkaline elements and inorganic ion being released from biochar (Fig. S2). The final pH of RS100R, RS300R, RS400R, RS500R, RS700R were around 3.5, 3.7, 3.8, 4.0, 4.4 with initial $\mathrm{pH} 3.5$ (Fig. 2), indicating that the $\mathrm{pH}$ increased by biochar residue 217 amendment was limited. In addition, the results of FTIR and XRD spectra confirmed that the dissolved organic matters and inorganic ions were released into the solution as biochar colloids (Fig. S1 and Fig. S2). These components released from biochar mainly affected the adsorption performance of biochar. The $\operatorname{Cr}(\mathrm{III})$ adsorption by biochar colloids is provided on Fig. 1. Surprisingly, the $\mathrm{Cr}(\mathrm{III})$ adsorption by biochar colloids was higher than that by biochar residues. For RS100C, the adsorption capacity between RS100C and RS100R were more or less the same at the initial pH3.0. As the pH was increased, the adsorption capacity for $\mathrm{Cr}(\mathrm{III})$ by $\mathrm{RS} 100 \mathrm{C}$ was higher than that of 
232

233

234

235

236

237

238

239

240

241

242

results were potentially caused by the colloidal effect and the $\mathrm{pH}$ increased by biochar colloids (Fig. 2). As colloids have higher specific surface areas and strong affinity, which results in biochar colloids being highly reactive (Gao et al., 2011). The biochar colloids contained numerous oxygen function groups and mineral matters, which could be served as the adsorption sites of $\mathrm{Cr}(\mathrm{III})$. Furthermore, the increasing $\mathrm{pH}$ may lead to transformation of $\mathrm{Cr}$ form to insoluble species, and also could activate the adsorption site (such as silicate particles) of biochar colloids. The highest $\mathrm{Cr}(\mathrm{III})$ adsorption was observed at RS400, which is consistent with the previous report about the $\mathrm{Al}$ adsorption by biochar (Qian \& Chen, 2013). The study found that the organic components and silicate particles within the biochars were served as dual adsorptive sites for $\mathrm{Al}$, as RS400 owned both of them, thus had the highest Al adsorption capacity.

The $\mathrm{Cd}(\mathrm{II})$ adsorption by biochar colloids confirmed the phenomenon obtained in $\mathrm{Cr}(\mathrm{III})$ adsorption by biochar colloids and residues (Fig. 3). The $\mathrm{Cd}(\mathrm{II})$ adsorption capacity by biochar colloids was higher than that of the correspondent biochar residue. When the initial $\mathrm{pH}$ was lower than 3.5 , similar to $\mathrm{Cr}(\mathrm{III})$, the highest $\mathrm{Cd}$ (II) adsorption capacity by RS100C, RS300C, RS400C, RS500C and RS700C were obtained at 2.75, 9.00, 14.56, 13.54 and $10.80 \mathrm{mg} / \mathrm{g}$ at initial $\mathrm{pH} 3.5$, respectively. These compared with the highest Cd adsorption capacity by RS100R, RS300R, RS400R, RS500R and RS700R achieved at $1.13,3.28,6.68,7.54$ and $5.83 \mathrm{mg} / \mathrm{g}$ at initial $\mathrm{pH} 3.5$, respectively. When the initial $\mathrm{pH}$ was higher above 3.5, the highest adsorption capacity for both biochar colloids and residues were reached at initial $\mathrm{pH} 4.5$. The highest adsorption 
capacity of RS500C $(39.0 \mathrm{mg} / \mathrm{g})$ and RS700C $(45.8 \mathrm{mg} / \mathrm{g})$ were two orders of magnitudes greater than those of RS500R (19.0 mg/g) and RS700R (20.4 mg/g), respectively, which was potentially caused by their high content of alkaline and mineral elements (Fig. S1 and Fig. S3). As the final pH of RS500 and RS700 were higher above 7.0 in case of the initial $\mathrm{pH} 4.5$ (Fig. S3), the precipitation of Cd was one of reasons for the high Cd(II) removal by RS500 and RS700.

The effect of $\mathrm{pH}$ on $\mathrm{Cr}(\mathrm{VI})$ removed by biochar colloids and residues are presented in Fig. 4. For biochars pyrolysed at low temperatures (RS100, RS300 and RS400), the $\mathrm{Cr}(\mathrm{VI})$ removal capacity of biochar colloids was higher than that of correspondence biochar residues. Unlike the adsorption behavior of the cationic heavy metals by biochar, the removal capacity of $\mathrm{Cr}(\mathrm{VI})$ by biochar colloids and residues was decreased significantly with increasing solution $\mathrm{pH}$, but the removal capacity between them has significant differences. At the initial $\mathrm{pH} 1.5$, the adsorption capacity of $\mathrm{Cr}(\mathrm{VI})$ by RS100C was reached $11.15 \mathrm{mg} / \mathrm{g}$, which is about 3 times higher than that of RS100R $\mathrm{Cr}$ (III) under acid conditions in the presence of oxygen-containing organic components. Previous studies have shown that the biomaterials present in nature could lead to the capacity of $\mathrm{Cr}(\mathrm{VI})$ by both the biochar colloids and residues have been declined significantly. When the initial $\mathrm{pH}$ was raised to 4.0 , the adsorption capacity of $\mathrm{Cr}(\mathrm{VI})$ by 
RS100C and RS100R was decreased to 2.13 and $0.48 \mathrm{mg} / \mathrm{g}$, respectively. Remarkably, the removal capacity of $\mathrm{Cr}(\mathrm{VI})$ by biochar colloids pyrolysed at higher temperature was

276 falling sharply. At an initial $\mathrm{pH} 1.5$, the removal capacity of $\mathrm{Cr}(\mathrm{VI})$ by RS300C, RS400C, RS500C and RS700C were 11.02, 7.91, 4.42 and $1.34 \mathrm{mg} / \mathrm{g}$ respectively. As greater mobility was observed for the smaller particle sizes of biochar (Wang et al., 2013a), this phenomenon indicated that the risk of $\mathrm{Cr}(\mathrm{VI})$ migrating to groundwater was reduced 
the removal of high mobility of $\mathrm{Cr}(\mathrm{VI})$ by biochar, it was found that as the biochar pyrolysis temperatures were raised, the removal capacity of $\mathrm{Cr}(\mathrm{Vl})$ by biochar colloids were decreasing, and that of $\mathrm{Cr}(\mathrm{Vl})$ by biochar residues were firstly increasing then maintaining at a high level, thereby reducing the risk of groundwater contaminated by $\operatorname{Cr}(\mathrm{Vl})$.

To better understand the removal characteristics of biochar, the total $\mathrm{Cr}$ removal by the biochar colloids and residues were also investigated (Fig.4). As illustrated in Fig. 4, total $\mathrm{Cr}$ removal capacity by biochar colloids were significantly higher than that of biochar residues. At initial $\mathrm{pH} 1.5$, total $\mathrm{Cr}$ removal capacities by biochar colloids were 28.32, 25.33, 22.52, 19.69 and $16.17 \mathrm{mg} / \mathrm{g}$ for RS300C, RS400C, RS500C, RS100C and RS700C respectively. At $\mathrm{pH} 1.5$, total $\mathrm{Cr}$ removal capacities by biochar residues were $11.62,10.67,9.74,9.01$ and $7.86 \mathrm{mg} / \mathrm{g}$ respectively for RS300C, RS400C, RS700C, RS500C and RS100C.The above results showed that the total $\mathrm{Cr}$ removal capacity by biochar colloids was about two times higher than those of the corresponding biochar residues. This phenomenon was mainly due to the biochar colloids rich of dissolved organic matters and inorganic minerals, these substances have a strong capability on chromium fixation with biochar colloids having very strong colloidal effects, thus a combination of these characteristics enhanced the $\mathrm{Cr}$ removal by biochar colloids (Dong et al., 2014; Gao et al., 2011; Kumari et al., 2014; Zhang et al., 2013). Among biochars pyrolysed at the different temperatures, total Cr removal capacity for RS300 ranked the highest, this may be related to biochar having large amounts of organic components, 
such as the oxygen-containing functional groups and a certain amount of mineral

317 components, and both of the two components contributed to the total $\mathrm{Cr}$ removal by

318 RS300 (Dong et al., 2014; Hsu et al., 2009; Shen et al., 2012).

3.3 Mechanisms of heavy metal removal by biochar colloid and biochar residue

The heavy metal removal by the biochar colloids and residues were investigated under different pyrolysis temperatures. For cationic heavy metal $(\mathrm{Cr}(\mathrm{III})$ and $\mathrm{Cd}(\mathrm{II})$, the representative cationic heavy metal), RS400 was the most effective adsorbent for $\mathrm{Cr}(\mathrm{III})$ and $\mathrm{Cd}(\mathrm{II})$ under initial $\mathrm{pH}$ 3.5. These results were potentially caused by it contains oxygen function groups and mineral matters simultaneously and the $\mathrm{pH}$ increasing. As the oxygen function groups and mineral matters could be served as the adsorption sites of $\mathrm{Cr}(\mathrm{III})$ and $\mathrm{Cd}(\mathrm{II})$. Furthermore, the increasing $\mathrm{pH}$ may lead to the transformation of $\mathrm{Cr}$ and $\mathrm{Cd}$ form to insoluble species, and could activate the adsorption sites (such as silicate particles) of biochar colloids. This was consistent with the Al adsorption behavior by biochar, indicating that both the organic components and mineral matter within the biochars contributed to heavy metal adsorption by biochar. For $\operatorname{Cr}(\mathrm{VI})$ (commonly existed as chromate $\left(\mathrm{CrO}_{4}{ }^{2-}, \mathrm{HCrO}_{4}{ }^{-}\right)$and dichromate $\left(\mathrm{Cr}_{2} \mathrm{O}_{7}{ }^{2-}\right), \mathrm{RS} 300$ was the most effective for $\mathrm{Cr}(\mathrm{VI})$ removal. The primarily responsible for the $\mathrm{Cr}(\mathrm{VI})$ removal were the reduction and adsorption. The phenolic groups and hydroxyl groups in biochar are responsible for $\mathrm{Cr}(\mathrm{VI})$ reduction, and the mineral matter and other oxygen functional groups are contributed to the $\mathrm{Cr}(\mathrm{VI})$ adsorption by biochar (Dong et al., 2014; Hsu et al., 2009). As RS300 owned both of them, thus had the highest $\mathrm{Cr}(\mathrm{VI})$ removal amount. 

that the removal rate of heavy metal by biochar colloid was higher than that of corresponding biochar residue except the $\mathrm{Cr}(\mathrm{VI})$ removal by RS500 and RS700. The high removal rate of $\mathrm{Cr}(\mathrm{III})$ and $\mathrm{Cd}(\mathrm{II})$ could be attributed to the numerous content of oxygen function group (Fig. S1) and mineral matter (Fig. S2). And the phenolic functional groups contained in RS100 and RS300 mainly the reason of high removal of $\mathrm{Cr}(\mathrm{VI})$. However, when the pyrolysis temperature increased (RS500 and RS700), the $\mathrm{Cr}(\mathrm{VI})$ removal rate by biochar residue was higher than that of biochar colloid. It is well known that colloid can be mobilized and transported by water flow to a distance in soil and groundwater environments (Sen \& Khilar, 2006). Colloid-facilitated transport has metals mobiles in soils and groundwater (Grolimund \& Borkovec, 2005). The high removal rate of $\mathrm{Cr}(\mathrm{III})$ and $\mathrm{Cd}(\mathrm{II})$ by biochar colloid could induced the heavy metal mobility enhanced, thus increased the risk of cationic heavy metal contamination in groundwater. Remarkably, as pyrolysis temperature increased, the $\mathrm{Cr}(\mathrm{VI})$ removal by biochar colloid was decreased, indicating that the potential risk of anionic heavy metal contamination in groundwater was decreased.

\section{Conclusions}

The structures of biochar colloids were different from those of biochar residues. Biochar colloids contain numerous oxygen function groups and mineral matters obtained under low and high pyrolysis temperatures. The high contents of oxygen function groups and mineral matters in biochar colloids lead to the high removal of 
$\mathrm{Cr}(\mathrm{III})$ and $\mathrm{Cd}(\mathrm{II})$. The phenolic functional groups contained in RS100 and RS300

resulted in the enhancement of $\mathrm{Cr}(\mathrm{VI})$ reduction, and the $\mathrm{Cr}(\mathrm{VI})$ removal by biochar

residues was higher than that of biochar colloids when the pyrolysis temperature was increased (RS500 and RS700).

363

364

\section{Acknowledgments}

365

This project is supported by the National Science Foundation of China (Grants No. 21507138), the Natural Science Foundation of Jiangsu Pvovince, China (Grants No. SBK2015041561), the National High Technology Research and Development Program (2013AA06A208), the National Science Foundation of China (41471404).

\section{Reference}

Cantrell, K., Hunt, P., Uchimiya, M., Novak, J., Ro, K., 2012. Impact of pyrolysis temperature and manure source on physicochemical characteristics of biochar. Bioresour. Technol. 107, 419-428.

Cao, X., Harris, W., 2010. Properties of dairy-manure-derived biochar pertinent to its potential use in remediation. Bioresour. Technol. 101(14), 5222-5228.

Chen, B., Yuan, M., Qian, L., 2012. Enhanced bioremediation of PAH-contaminated soil by immobilized bacteria with plant residue and biochar as carriers. J. Soil. 
Chen, B., Zhou, D., Zhu, L., 2008. Transitional adsorption and partition of nonpolar and polar aromatic contaminants by biochars of pine needles with different pyrolytic temperatures. Environ. Sci. Technol. 42(14), 5137-5143.

Chen, Z., Xiao, X., Chen, B., Zhu, L., 2015. Quantification of chemical states, dissociation constants and contents of oxygen-containing groups on the surface of biochars produced at different temperatures. Environ. Sci. Technol. 49(1), 309-317.

Dong, X., Ma, L.Q., Gress, J., Harris, W., Li, Y., 2014. Enhanced Cr(VI) reduction and As(III) oxidation in ice phase: Important role of dissolved organic matter from biochar. J. Hazard. Mater. 267, 62-70.

Eusterhues, K., Rennert, T., Knicker, H., Kogel-Knabner, I., Totsche, K., Schwertmann, U., 2011. Fractionation of organic matter due to reaction with ferrihydrite: coprecipitation versus adsorption. Environ. Sci. Technol. 45(2), 527-533.

Fang, G., Zhu, C., Dionysiou, D., Gao, J., Zhou, D., 2015. Mechanism of hydroxyl radical generation from biochar suspensions: Implications to diethyl phthalate degradation. Bioresour. Technol. 176, 210-217.

Gao, B., Cao, X., Dong, Y., Luo, Y., Ma, L.Q., 2011. Colloid deposition and release in soils and their association with heavy metals. Cri. Rev. Environ. Sci. Technol. 41(4), 336-372.

Grolimund, D., Borkovec, M., 2005. Colloid-facilitated transport of strongly sorbing 
contaminants in natural porous media: mathematical modeling and laboratory column experiments. Environ. Sci. Technol. 39(17), 6378-6386.

Hsu, N., Wang, S., Lin, Y., Sheng, G., Lee, J., 2009. Reduction of Cr(VI) by crop-residue-derived black carbon. Environ. Sci. Technol. 43(23), 8801-8806.

Kumari, K., Moldrup, P., Paradelo, M., Elsgaard, L., Hauggaard-Nielsen, H., de Jonge, L., 2014. Effects of biochar on air and water permeability and colloid and phosphorus leaching in soils from a natural calcium carbonate gradient. J. Environ. Qual. 43(2), 647-657.

Lead, J., Wilkinson, K., 2006. Aquatic colloid and nanoparticles: current knowledge and future trends. Environ.Chem. 3(3), 159-171.

Li, A., Zhao, X., Mao, R., Liu, H., Qu, J., 2014. Characterization of dissolved organic matter from surface waters with low to high dissolved organic carbon and the related disinfection byproduct formation potential. J. Hazard. Mater. 271, 228-235.

Manoharan, V., 2015. Colloidal matter: packing, geometry, and entropy. Science 349(6251), 1253751-1-1253751-7.

Matilainen, A., Gjessing, E., Lahtinen, T., Hed, L., Bhatnagar, A., Sillanpaa, M., 2011. An overview of the methods used in the characterisation of natural organic matter (NOM) in relation to drinking water treatment. Chemosphere 83(11), 1431-1442.

Oren, A., Chefetz, B., 2012. Sorptive and desorptive fractionation of dissolved organic 
matter by sineral soil matrices. J. Environ. Qual. 41(2), 526-533.

424 Park, D., Lim, S., Yun, Y., Park, J., 2007. Reliable evidences that the removal mechanism of hexavalent chromium by natural biomaterials is adsorption-coupled reduction. Chemosphere 70(2), 298-305.

Qian, L., Chen, B., 2013. Dual role of biochars as adsorbents for aluminum: The effects of oxygen-containing organic components and the scattering of silicate particles. Environ. Sci. Technol. 47(15), 8759-8768.

Qian, L., Chen, B., 2014. Interactions of aluminum with biochars and oxidized biochars: Implications for the biochar aging process. J. Agricul. Food Chem. 62(2), 373-380.

Qian, L., Chen, B., Hu, D., 2013. Effective alleviation of aluminum phytotoxicity by manure-derived biochar. Environ. Sci. Technol. 47(6), 2737-45.

Qian, L., Chen, M., Chen, B., 2015. Competitive adsorption of cadmium and aluminum onto fresh and oxidized biochars during aging processes. J. Soil. Sediment. 15(5), 1130-1138.

Sen, T., Khilar, K., 2006. Review on subsurface colloid and colloid-associated contaminant transport in saturated porous media. Adv. Colloid Interfac. 119(2-3), 71-96.

Shen, Y., Wang, S., Tzou, Y., Yan, Y., Kuan, W., 2012. Removal of hexavalent Cr by coconut coir and derived chars - the effect of surface functionality. Bioresour. Technol. 104, 165-172. 
Uchimiya, M., Chang, S., Klasson, K., 2011. Screening biochars for heavy metal retention in soil: role of oxygen functional groups. J. Hazard. Mater. 190(1-3), $432-441$.

Wang, D., Zhang, W., Hao, X., Zhou, D., 2013a. Transport of biochar particles in saturated granular media: effects of pyrolysis temperature and particle size. Environ. Sci. Technol. 47(2), 821-828.

Wang, D., Zhang, W., Zhou, D., 2013b. Antagonistic effects of humic acid and iron oxyhydroxide grain-coating on biochar nanoparticle transport in saturated sand. Environ. Sci. Technol. 47(10), 5154-5161.

Xiao, X., Chen, B., Zhu, L., 2014. Transformation, morphology, and dissolution of silicon and carbon in rice straw-derived biochars under different pyrolytic temperatures. Environ. Sci. Technol. 48(6), 3411-3419.

Yan, J., Han, L., Gao, W., Xue, S., Chen, M., 2015. Biochar supported nanoscale zerovalent iron composite used as persulfate activator for removing trichloroethylene. Bioresour. Technol. 175, 269-274.

Zhang, W., Mao, S., Chen, H., Huang, L., Qiu, R., 2013. Pb(II) and Cr(VI) sorption by biochars pyrolyzed from the municipal wastewater sludge under different heating conditions. Bioresour. Technol. 147, 545-552.

Zhang, W., Niu, J., Morales, V.L., Chen, X., Hay, A., Lehmann, J., Steenhuis, T., 2010. Transport and retention of biochar particles in porous media: effect of $\mathrm{pH}$, ionic strength, and particle size. Ecohydrology 3(4), 497-508. 
476

477

478

479

480

481

482

483

484

485

486 86

Zheng, R., Cai, C., Liang, J., Huang, Q., Chen, Z., Huang, Y., Arp, H., Sun, G., 2012. The effects of biochars from rice residue on the formation of iron plaque and the accumulation of $\mathrm{Cd}, \mathrm{Zn}, \mathrm{Pb}, \mathrm{As}$ in rice (Oryza sativa L.) seedlings. Chemosphere 89(7), 856-862.

Zhu, W., Yao, W., Zhang, Z., Wu, Y., 2014. Heavy metal behavior and dissolved organic matter (DOM) characterization of vermicomposted pig manure amended with rice straw. Environ. Sci. Pollut. R. 21(22), 12684-12692.

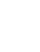

\section{3}

4

5

6

77

8

79

80

81

\section{2}

3 84 85 
TABLE 1. Elemental Compositions and Atomic Ratios of the Biochar Colloid and Residue Samples Produced under Different Temperatures. The "C" and "R" represent "Colloid" and "Residue" respectively.

Fig. 1 Effect of $\mathrm{pH}$ on $\mathrm{Cr}(\mathrm{III})$ adsorption by the biochar colloid and residue samples produced under differrent temperatures. The "C" and "R" represent "Colloid" and "Residue" respectively.

Fig. 2. The $\mathrm{pH}$ changes during $\mathrm{Cr}$ adsorption by the biochar colloid and residue samples produced under different temperatures. The "C" and "R" represent "Colloid" and "Residue" respectively.

Fig. 3 Effect of $\mathrm{pH}$ on $\mathrm{Cd}$ adsorption by the biochar colloid and residue samples produced under different temperatures. The "C" and "R" represent "Colloid" and "Residue" respectively.

Fig. 4 Effect of $\mathrm{pH}$ on $\mathrm{Cr}(\mathrm{VI})$ removed by the biochar colloid and residue samples produced under different temperatures. The "C" and " $\mathrm{R}$ " represent "Colloid" and "Residue" respectively. 
510 TABLE 1. Elemental compositions and atomic ratios of the biochar colloid and residue 511 samples produced under different temperatures. The "C" and "R" represent "Colloid" 512 and "Residue" respectively.

\begin{tabular}{cccccc}
\hline Samples & N (\%) & $\mathbf{C ~ ( \% )}$ & $\mathbf{H}(\mathbf{\%})$ & $\mathbf{O}(\mathbf{\%})$ & $\mathbf{H} / \mathbf{C}$ \\
\hline RS100C & 1.10 & 34.48 & 5.38 & 45.39 & 1.87 \\
RS300C & 0.61 & 33.33 & 3.06 & 28.01 & 1.10 \\
RS400C & 0.59 & 25.79 & 2.03 & 23.77 & 0.94 \\
RS500C & 0.45 & 23.52 & 1.81 & 30.72 & 0.92 \\
RS700C & 0.01 & 24.65 & 1.15 & 27.04 & 0.56 \\
RS100R & 0.34 & 40.81 & 5.94 & 50.91 & 1.75 \\
RS300R & 0.69 & 50.21 & 4.45 & 28.91 & 1.06 \\
RS400R & 0.65 & 50.02 & 3.63 & 25.55 & 0.87 \\
RS500R & 0.52 & 50.84 & 3.28 & 19.21 & 0.77 \\
RS700R & 0.70 & 49.01 & 2.14 & 21.62 & 0.52 \\
\hline
\end{tabular}



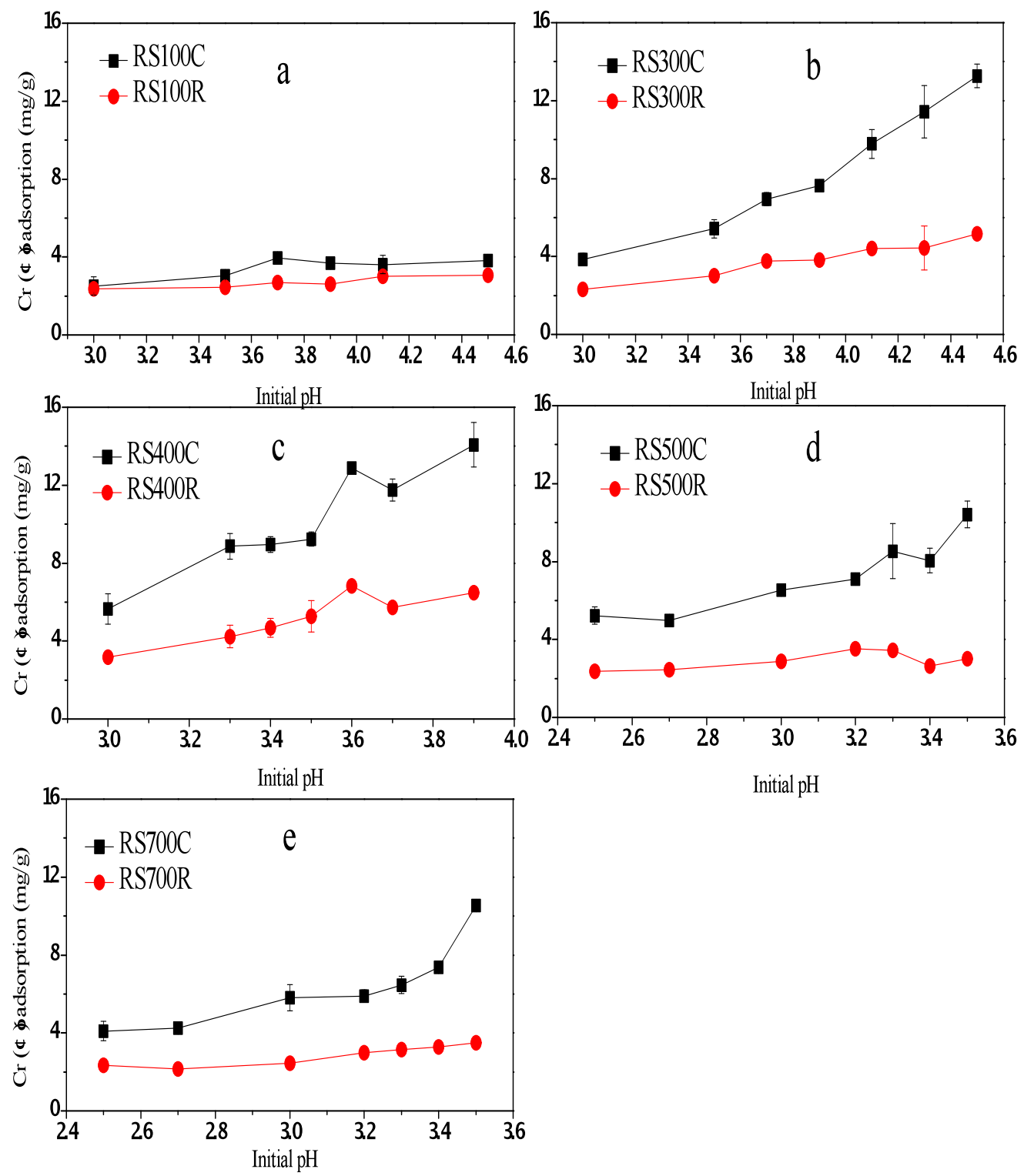

519 Fig. 1 Effect of $\mathrm{pH}$ on $\mathrm{Cr}(\mathrm{III})$ adsorption by the biochar colloid and residue samples

520 produced under differrent temperatures. The " $C$ " and " $\mathrm{R}$ " represent "Colloid" and 521 "Residue" respectively. 

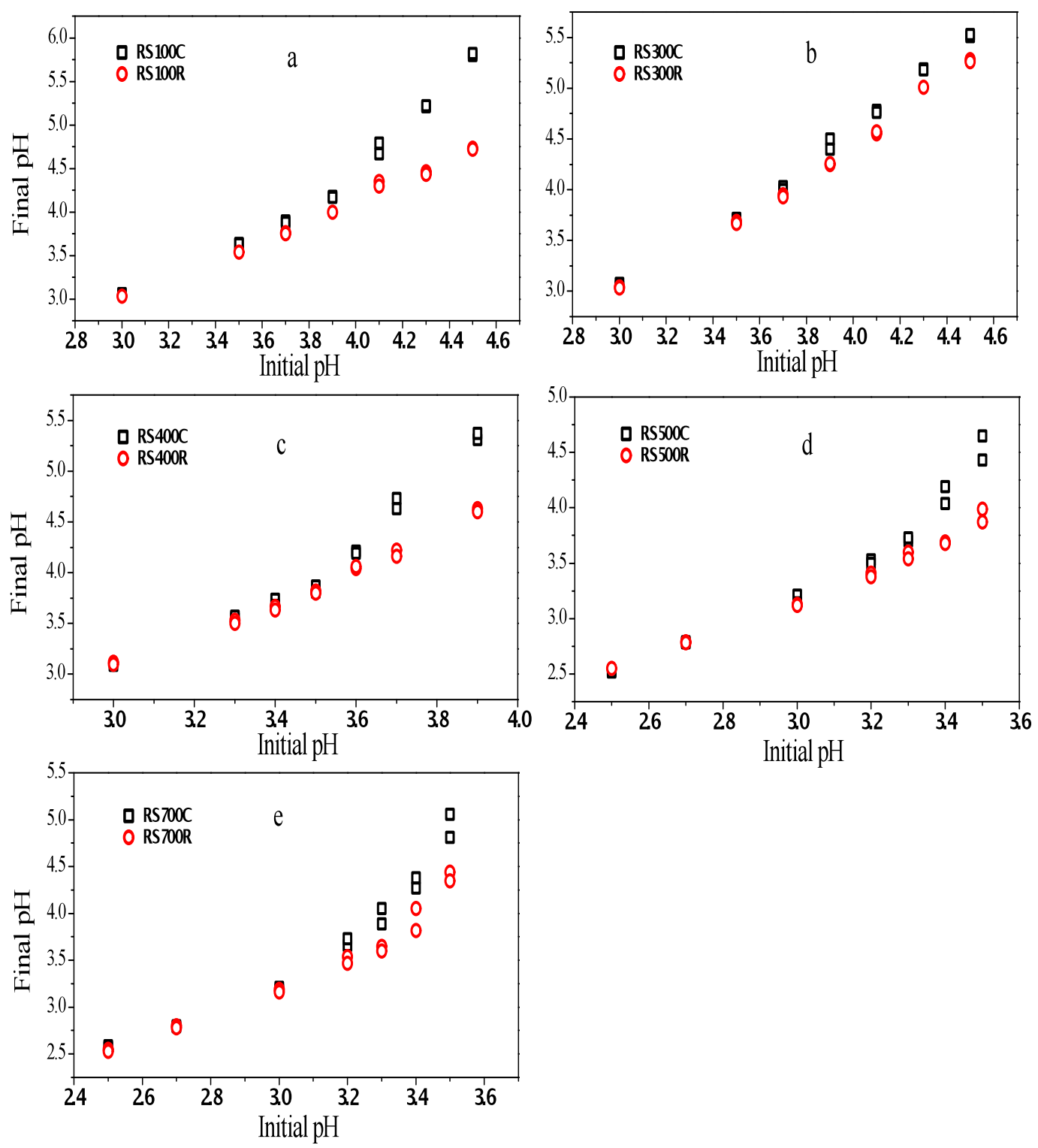

522

523 Fig. 2 The $\mathrm{pH}$ changes during $\mathrm{Cr}$ adsorption by the biochar colloid and residue samples

524 produced under different temperatures. The " $\mathrm{C}$ " and " $\mathrm{R}$ " represent "Colloid" and "Residue" respectively. 

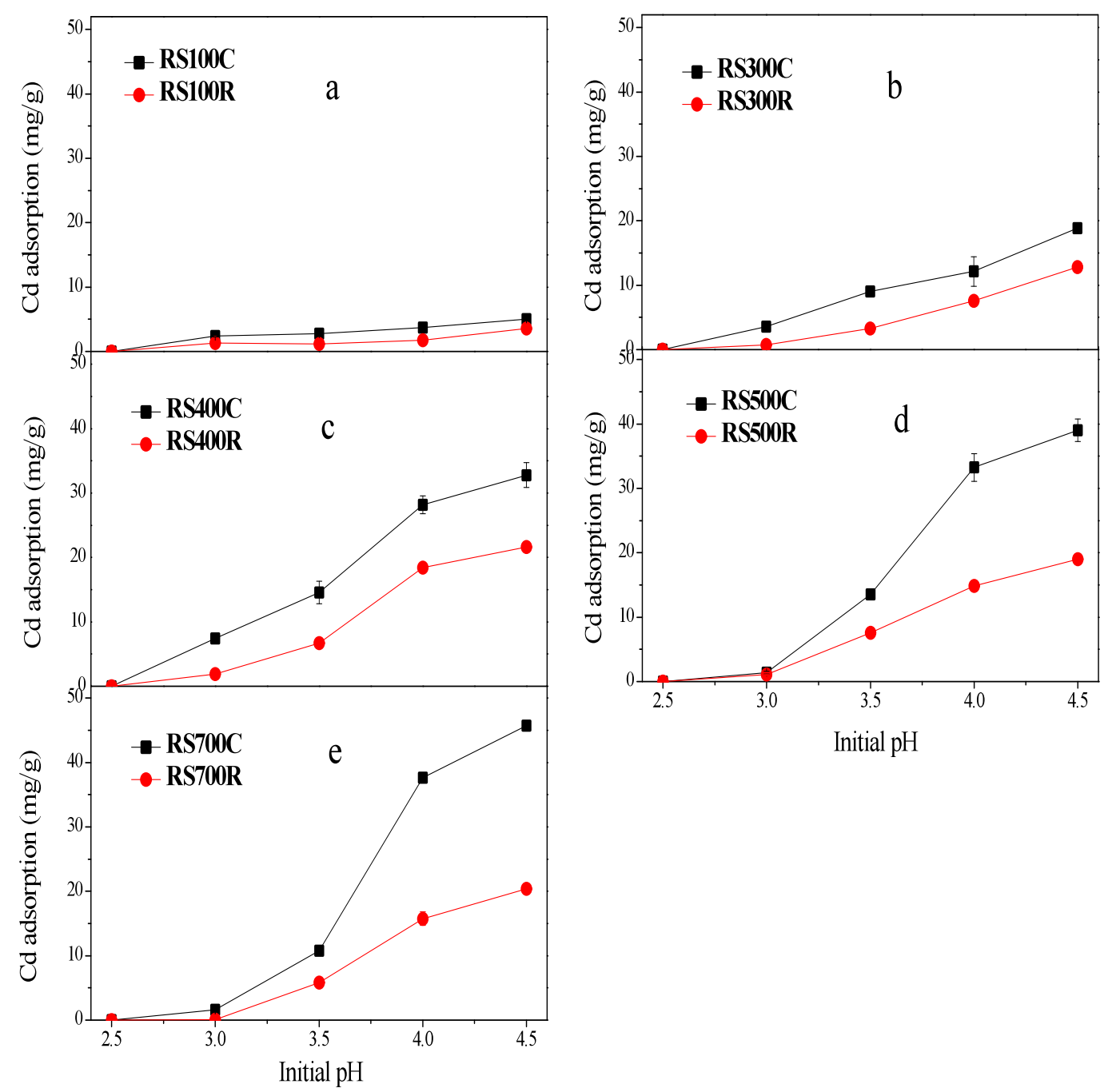

528 Fig. 3 Effect of $\mathrm{pH}$ on $\mathrm{Cd}$ adsorption by the biochar colloid and residue samples 529 produced under different temperatures. The "C" and " $R$ " represent "Colloid" and 530 "Residue" respectively. 

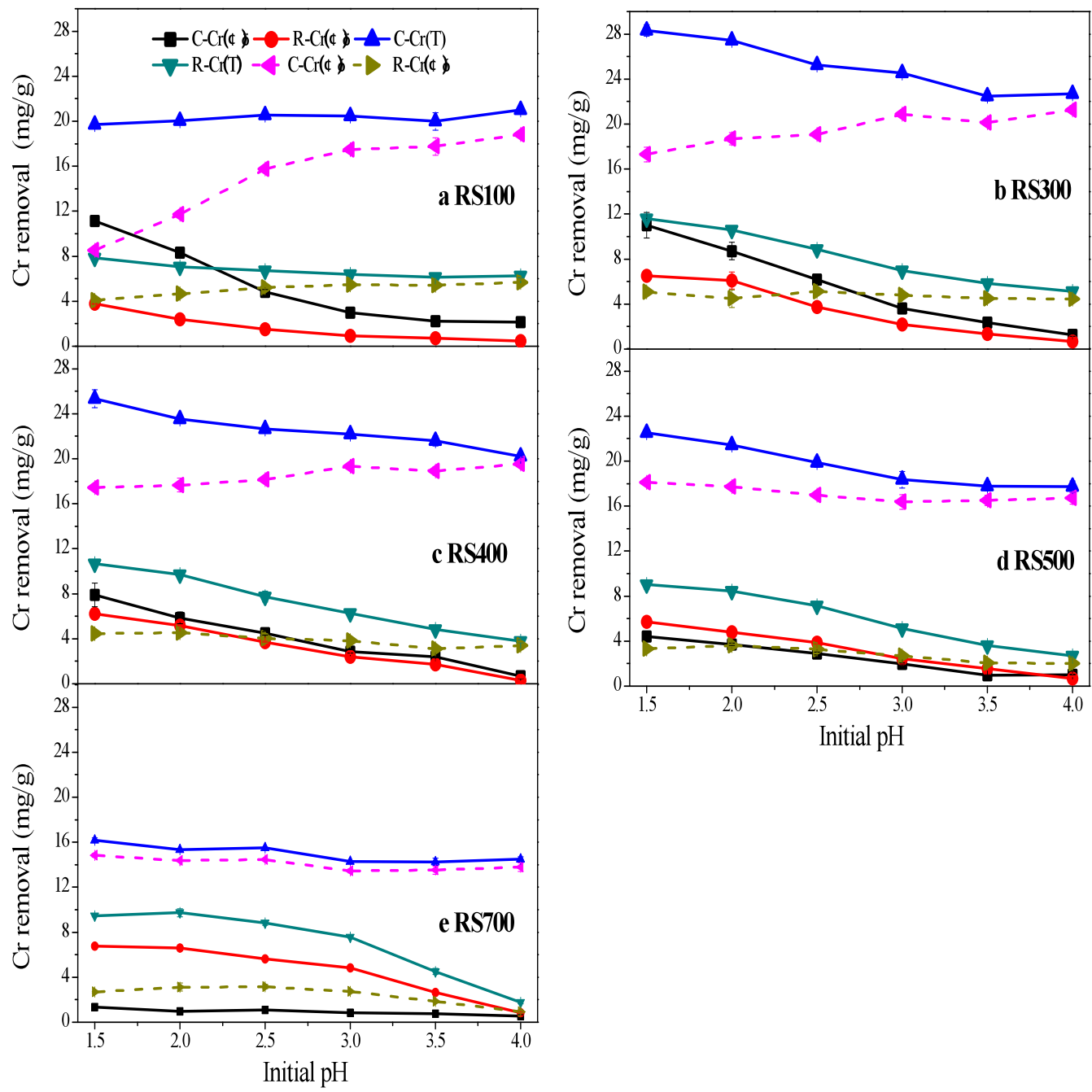

534 Fig. 4 Effect of $\mathrm{pH}$ on $\mathrm{Cr}(\mathrm{VI})$ removed by the biochar colloid and residue samples 535 produced under different temperatures. The "C $\mathrm{C}$ " and " $\mathrm{R}$ " represent "Colloid" and 536 "Residue" respectively. 


\section{Graphical Abstract}

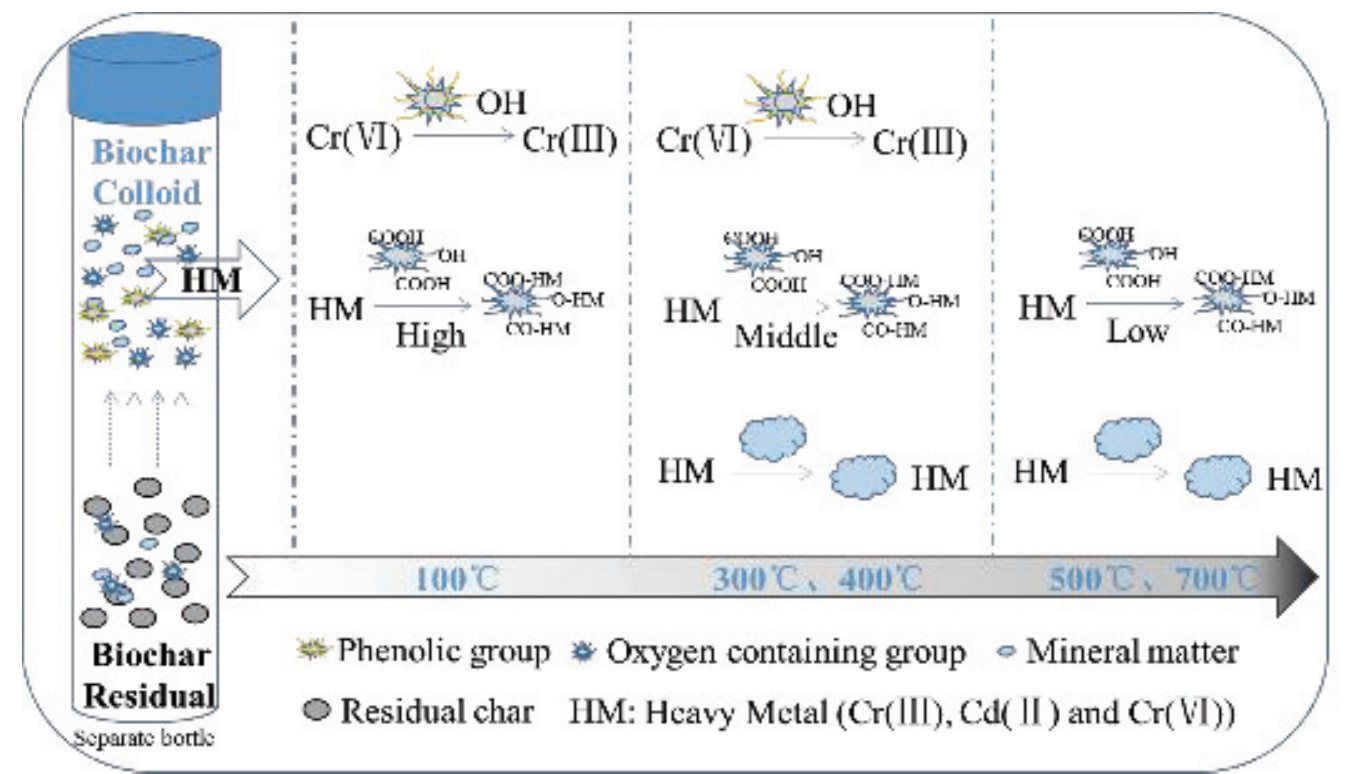

Effective removal of heavy metals by biochar colloids under different pyrolysis temperatures 